\title{
The influence of wrench tectonics on submarine volcanism in the NE Lau Basin (Tonga)
}

ChantAl nORRIS-JUlSETH ${ }^{1}$, MElisSA O. ANDERSON ${ }^{1}$, KEN RUBIN ${ }^{2}$, KARSTEN HAASE ${ }^{3}$, MARK HANNINGTON ${ }^{4,5}$, AlAN BAXTER $^{4}$, MARGARET StEWART ${ }^{4}$

${ }^{1}$ Dept. of Earth Sciences, Univ. of Toronto, 22 Russell St,

Toronto, Canada; melissao.anderson@utoronto.ca

${ }^{2}$ Department of Geology and Geophysics, SOEST, Univ. of

Hawaii, 1680 East-West Road, Honolulu, Hawaii, USA

${ }^{3}$ GeoZentrum Nordbayern, Friedrich-Alexander Univ. of

Erlangen-Nürnberg, Schlossgarten 5, Erlangen, Germany

${ }^{4}$ Dept. of Earth Sciences, University of Ottawa, 25

Templeton, Ottawa, Canada

${ }^{5}$ GEOMAR, Helmholtz Centre for Ocean Research Kiel,

Wischhofstrasse 1-3, Kiel, Germany

The NE Lau Basin is one of the most dynamic places on the planet, characterized by ultra-fast subduction rates (24 $\mathrm{cm} / \mathrm{yr}$; [1]), and back-arc spreading distributed among several spreading centers. The Tonga trench has a sharp bend at it's northernmost extent, where there is a transition from convergence to transform motion. We explore the complex structural evolution of the NE Lau Basin, and it's influence on submarine volcanism, using nearly-continuous bathymetric data collected over several research cruises in the past decade (KM1024, KM1129, FK171110, and SO-263). Interpretations of the seafloor topography, combined with seafloor observations and rock sampling, have been combined to produce a remote-predictive geological map over $\sim 40,760$ $\mathrm{km}^{2}$. This mapping highlights the abundance of off-axis distributed volcanism, manifest as extensive lava flows, large volcanic ridges with various orientations, and point-source volcanoes that sample a heterogenous mantle wedge, with sharp gradients and contrasts, including the presence of enriched and depleted compositions, and arc-affinity magmatism and non-affinity magmatism in different regions. Structural lineament analyses combined with CMT analysis reveal that the volcanic-compositional provinces are aligned with Riedel shear structures associated with wrench tectonics along the northern transform boundary. Importantly, two distinct sets of Riedel shears are identified, associated with a counter-clockwise rotation in the stress field, which we propose is related to collision with the Capricorn Seamount. The style of faulting is dominated by the reactivation of preexisting structures. This study highlights the importance of seamount collisions on the structural and volcanic evolution of a back-arc basin.

[1] Bevis et al., 1995; Nature 